\title{
Wawasan Nusantara : Sebagai Satu Kesatuan, Politik, Ekonomi, Sosial, Budaya dan Hankam di Indonesia
}

\author{
Rosita Silfiani \\ Institut Ilmu Kesehatan STRADA Indonsia \\ rositasilfiani@gmail.com
}

\begin{abstract}
Abstrak
Wawasan nusantara merupakan cara pandang bangsa tentang dirinya ditengahtengah lingkungan strategis yang bergerak serba cepat dan dinamik, agar bangsa tersebut tetap eksis dan survief. Bangsa Indonesia sebagai salah satu negara yang menjunjung tinggi wawasan nusantara sebagai upaya pelestarian pengetahuan nusantara dan tidak pernah menninggalkan unsur-unsur penting didalamnya. Unsur penting tersebut meliputi : persatuan dan kesatuan, politik, ekonomi, sosial budaya dan hankam. wawasan nusantara yang merupakan wawasan nasional yang bersumber pada Pancasila dan berdasarkan UUD 1945 adalah cara pandang dan sikap bangsa Indonesia mengenai diri dan lingkungannya dengan mengutamakan persatuan dan kesatuan bangsa serta kesatuan wilayah dalam menyelenggarakan kehidupan bermasyarakat, berbangsa, dan bernegara untuk mencapai tujuan nasional.
\end{abstract}

Kata Kunci : Wawasan Nusantara, persatuan dan kesatuan 


\section{Latar Belakang}

Wawasan nusantara merupakan cara pandang bangsa tentang dirinya ditengahtengah lingkungan strategis yang bergerak serba cepat dan dinamik, agar bangsa tersebut tetap eksis dan survief. Pengertian lain dari wawasan nusantara secara terminology diartikan sebagai cara pandang sebuah nation state tentang diri dan lingkungan strategiknya yang berubah serta dinamik dengan mempertimbangkan aspek cultural, histories, geografis, ruang lingkup, idealisme, falsafah negara, konstitusi, aspirasi, identitas, integritas kelangsungan hidup dan perkembangan kehidupannya serta kemampuan daya saingnya.

Pengertian wawasan nusantara berdasarkan ketetapan MPR Tahun 1993 dan 1998 tentang GBHN adalah sebagai berkut : wawasan nusantara yang merupakan wawasan nasional yang bersumber pada Pancasila dan berdasarkan UUD 1945 adalah cara pandang dan sikap bangsa Indonesia mengenai diri dan lingkungannya dengan mengutamakan persatuan dan kesatuan bangsa serta kesatuan wilayah dalam menyelenggarakan kehidupan bermasyarakat, berbangsa, dan bernegara untuk mencapai tujuan nasional.

Sebagai bangsa yang bernegara, bangsa Indonesia dalam membina dan membangun kehidupan nasional, baik pada aspek politik, ekonomi, sosial budaya maupun hankam, selalu mengutamakan persatuan dan kesatuan bangsa serta kesatuan wilayah. Maka dari itu dalam pembinaan dan penyelenggaraantat kehidupan bangsa dan negara Indonesia disusun atas dasar hubungan timbal balik antara falsafah, cita-cita dan tujuan nasional, serta kondisi sosial budaya dan pengalaman sejarah yang dapat menumbuhkan kesadaran tentang kemajemukan dan kebhinekaan dengan mengutamakan persatuan dan kesatuan nasional.

Wawasan nusantara sebagai suatu kesatuan politik, ekonomi, sosial budaya dan hankam merupakan suatu pedoman yang dibutuhkan dalam suatu negara. Dimana Bangsa Indonesia sebagai salah satu negara yang menjunjung tinggi wawasan nusantara sebagai upaya pelestarian pengetahuan nusantara dan tidak pernah menninggalkan unsur-unsur penting didalamnya. Unsur penting tersebut meliputi : persauan dan kesatuan, politik, ekonomi, sosial budaya dan hankam. 


\section{Kasus/Masalah}

Berdasarkan latar belakang diatas maka dapat ditentukan kasus/masalah sebagai berikut:

1. Apakah pengertian dari Wawasan Nusantara?

2. Bagaimanakah cara meningkatkan Wawasan Nusantara?

3. Apakah isi Wawasan Nusantara?

\section{Tinjauan Pustaka}

\subsection{Pengertian Wawasan Nusantara}

Wawasan Nusantara merupakan Wawasan nusantara merupakan cara pandang bangsa tentang dirinya ditengah-tengah lingkungan strategis yang bergerak serba cepat dan dinamik, agar bangsa tersebut tetap eksis dan survief.

Ada bebrapa pengetian lain dari Wawasan Nusantara. Diantaranya adalah sebagai berikut:

1. Pengertian wawasan nusantara berdasarkan ketetapan MPR Tahun 1993 dan 1998 tentang GBHN adalah sebagai berkut : wawasan nusantara yang merupakan wawasan nasional yang bersumber pada Pancasila dan berdasarkan UUD 1945 adalah cara pandang dan sikap bangsa Indonesia mengenai diri dan lingkungannya dengan mengutamakan persatuan dan kesatuan bangsa serta kesatuan wilayah dalam menyelenggarakan kehidupan bermasyarakat, berbangsa, dan bernegara untuk mencapai tujuan nasional.

2. Menurut M.Pangabean (1979 : 349) Wawasan Nusantara adalah doktrin politik bangsa Indonesia untuk memepertahankan kelangsungan hidup Negara Kesatuan Republik Indonesia yang didasarkan pada Pancasila dan UUD 1945 dengan memperhitungkan pengaruh geografi, ekonomi, demografi, teknologi dan kemungkinan strategik yang tersedia. Denga perkataan lain, Wawasan Nusantara adalah geopolitik Indonesia. Dan nilai yang terkandung didalam wawasan nusantara telah diitegrasikan didalam lima aspek secara intern yaitu kesatuan wilayah, kesatuan bangsa, kesatuan ekonomi, kesatuan budaya dan kesatuan pertahanan, sedangkan untuk ekstern nilai integrasi diusahakan dengan ikut mewujudkan ketertiban dunia yang berdasarkan kemerdekaan perdamaian abadi dan keadilan sosial. 
3. Pengertian Wawasan Nusantara menurut Prof. DR. Wan usman. Wawasan Nusantara adalah cara pandnag bangsa Indonesia mengenai diri dan tanah airnya sebagai negara kepulauan dengan semua aspek kehidupan yang beragam.

4. Pengertian Wawasan Nusantara menurut kelompok kerja LEMHANAS 1999. Wawasan Nusantara adalah cara pandang dan sikap bangsa Indonesia megenai diri dan lingkungannya dengan mengutamakan persatuan dan kesatuan bangsa serta kesatuan wilayah dalam menyelenggarakan kehidupan bermasyarakat, berbangsa dan bernegara untuk mencapai tujuan nasional.

\subsection{Fungsi dan Tujuan Wawasan Nusantara}

\section{Fungsi}

Wawasan Nusantara berfungsi sebagai pedoman, motivasi, dorongan, serta rambu-rambu dalam menentukan segala kebijakasanaan, keputusan, tindakan, dan perbuatan bagi penyelenggaraan negara pada tingkat pusat dan daerah maupun bagi seluruh rakyat Indonesia dalam kehidupan bermasyarakat, berbangsa dan bernegara.

\section{Tujuan}

Wawasan Nusantara Bertujuan untukmmewujudkan Nasionalisme yang tinggi pada segala aspek kehidupan rakyat Indonesia yang lebih mengutamakan kepentingan nasional daripada kepentingan individu, kelompok, golongan, suku bangsa atau darah.

\subsection{Cara meningkatkan wawasan Nusantara}

Didalam persatuan dan kesatuan bangsa mengandung makna bahwa kita senantiasa harus Bersatu. Dalam sejarah diajarkan pentingnya peratuan dan kesatuan. Adapun cara meningkatkan rasa persatuan dan kesatuan melalaui Wawasan nusantara adalah sebgai berikut :

1. Meningkatkan samangat kekeluargaan, gotong royong, dan musyawarah

2. Meningkatkan kualitas hidup bangsa Indonesia dalam berbagai aspek kehidupan

3. Meratakan pembangunan serta keadilan sosial bagi seluruh rakyat Indonesia 
4. Melaksanakan otonomi daerah guna meningkatkan kesejahteraan masyarakat di daerah

5. Memperkuat sendi-sendi hukum nasional serta adanya kepastian hukum

6. Melindungi, menjamin, serta menjunjung tinggi hak asasi manusia

7. Memperkuat sistem pertahanan dan keamanan sehinga masyarakat merasa terlindungi.

\section{Pembahasan}

\subsection{Isi Wawasan Nusantara}

Isi Wawasan Nusantara tercermin dalam perspektif kehidupan manusia Indonesia dalam eksistensinya yang meliputi cita-cita bangsa dan asas manunggal yang terpadu.

a. Cita-cita bangsa Indonesia yang tertuang didalam pembukaan UUD 1945 yang menyebutkan bahwa :

1. Negara Indonesia yang merdeka, Bersatu, berdaulat adil dan Makmur.

2. Rakyat Indonesia yang berkehidupan kebangsaan yang bebas.

3. Pemerintah negara Indonesia melindungi segenap bangsa Indonesia dan seluruh tumpah darah Indonesia dan untuk memajukan kesejahteraan umum, mencerdaskan kehidupan bangsa, dan ikut melaksanakan ketertiban dunia yang berdasarkan kemerdekaan, perdamaian abadi dan keadilan sosial.

b. Asas keterpaduan semua aspek kehidupan nasional berisi manunggal, utuh, meneluruh yang meliputi :

1. Satu kesatuan wilayah nusantara yang mencakup daratan, perairan, dan dirgantara secara terpadu.

2. Satu kesatuan politik, dalam arti satu UUD dan politik pelaksanaannya serta satu ideologi dan identitas nasional.

3. Satu kestuan sosial-budaya, dalam arti satu perwujudan masyarakat Indonesia atas dasar "Bhineka Tunggal Ika" satu tertib sosial dan satu tertib hukum

4. Satu kesatuan ekonomi dengan berdasarkan atas asas usaha bersama dan asas kekeluargaan dalam satu sistem ekonomi kerakyatan. 
5. Satu kesatuan pertahanan dan keamanan dalam satu system terpadu yaitu sistem pertahanan keamanan rakyat semesta (Sishankamrata).

6. Satu kesatuan kebijakan nasional dalam arti pemerataan pembangunan dan hasil-hasilnya yang mencakup aspek kehidupan nasional.

4.2. Perwujudan Wawasan nusantara sebagai satu kesatuan politik

1. Kebulatan wilayah nasional dengan segala isi dan kekayaannya merupakan satu kesatuan wilayah dan milik bersama bangsa.

2. Keanekaragaman suku, budaya dan Bahasa daerah serta agama yang dianut tetap dalam kesatuan bangsa Indonesia.

3. Secara psikologis bangsa Indonesia merasa senasib, sepenangguhan, sebangsa dan setanah air, guna mencapai tekad dalam mencapai cita-cita bangsa

4. Pancasila adalah satu-satunya falsafah serta ideologi bangsa dan negara yang melandasi, membimbing dan mengarahkan bangsa menuju tujuannya.

5. Seluruh kepulauan nusantara merupakan satu kesatuan sistem hukum dalam ati hanya ada satu hukum nasional yang mengabdi kepada kepentingan nasional.

6. Bangsa Indonesia bersama bangsa-bangsa lain ikut menciptakan ketertiban dunia dan perdamaian abadai melalui politik luar negeri yang bebas aktif.

\subsection{Perwujudan Wawasan Nusantara sebagai satu kesatuan Ekonomi}

1. Kekayaan di wilayah nusantara, baik potensial maupun efektif adalah modal dan milik bersama bangsa.

2. Tingkat perkembangan ekonomi harus serasi dan seimbang di seluruh daerah, tanpa meninggalkan ciri khas satu sama lain.

3. Kehidupan perekonomian di seluruh wilayah Nusantara merupakan satu kesatuan ekonomi yang diselenggarakan sebagai usaha bersama atas asas kekeluargaan.

4.4. Perwujudan Wawasan Nusantara sebagai satu kesatuan Sosial Budaya

1. Masyarakat Indonesia adalah satu bangsa yang harus memiliki kehidupan serasi dengan tingkat kemajuan yang merata dan seimbang sesuai dengan kemajuan bangsa

2. Budaya Indonesia pada hakikatnya adalah satu kesatuan dengan corak ragam budaya yang menggambarkan kekayaan budaya bangsa. Budaya Indonesia 
tidak menolak nilai-nilai budaya asing asalkan tidak bertentangan dengan nilai budaya bangsa sendiri dan hasilnya dapat dimiliki.

\subsection{Perwujudan Wawasan Nusantara sebagi satu kesatuan Pertahanan Keamanan}

1. Bahwa ancaman terhadap satu pulau atau satu daerah pada hakikatnya merupakan ancaman terhadap seluruh bangsa dan negara

2. Bahwa tiap-tiapwarga negara mempunyai hak dan kewajiban yang sama dlam rangka pembelaan bangsa dan negara.

\section{Kesimpulan}

Pancasila adalah satu-satunya falsafah serta ideologi bangsa dan negara yang melandasi, membimbing dan mengarahkan bangsa menuju tujuannya yaitu terciptanya persatuan dan kesatuan. Sehingga dengan demikian Wawasan Nusantara sebagai aktualisasi falsafah Pancasila menjadi landasan dan pedoman bagi kelangsungan hidup bangsa dan negara Indonesia. Dapat disimpulkan bahwa Wawasan Nusantara merupakan pedoman sebagai upaya terujudnya persatuajn

Dan kesatuan aspek kehidupan nasional untuk menjamin kesatuan, peratuan, politik, ekonomi, sosial budaya dan hankam.

\section{Daftar Pustaka}

Adibowo, R. (2010). Wawasan Nusantara.

Awan, I., \& Sodik, M.A. (2018). Diskriminasi dan Kesehatan Mental.

Karina, Z., \& Sodik, M.A. Pengaruh Dukungan Soial Terhadap Kesehatan.

Lemhanas. (1982). Bunga Rampai wawasan Nusantara.

M. Budiyarto. (1980). Wawasan Nusantara Dalam Peraturan Perundang-undangan Negara Republik Indonesia. Penerbit : Ghalia Indonesia.

Surwati, S. (2013). Peranan Pengangkutan Udara di Indonesia Dalam menunjang Pengimplementasian wawasan Nusantara. Jurnal manajemn Dirgantara, 6(2), $51-58$. 